\title{
ERECTILE DYSFUNCTION AND ITS MANAGEMENT: AN UPDATE
}

\author{
Abdus Saleque Mollah ${ }^{1}$ Md Iftikher Hossain Khan ${ }^{2}$
}

\begin{abstract}
Summary
Erectile dysfunction (ED) defined as "the inability to achieve or maintain an erection sufficient for sexual intercourse"-is one of the most common sexual dysfunctions in men. Some men assume that erectile failure is a natural part of the aging process and tolerate it, for others it is devastating. Withdrawal from sexual intimacy because of fear of failure can damage relationships and have a profound effect on overall wellbeing for the couple. Erectile dysfunction often accompanies chronic illnesses, such as diabetes mellitus, heart disease, hypertension, and a variety of neurological diseases. Therefore, physicians need to identify any underlying co-existing organic diseases in their patients presenting with ED. Whenever possible, patients are encouraged to attend their consultation sessions with their partners because ED is a condition affecting 'the couple' and not just the man. Psychogenic aspects of ED should also be explored during the consultation. The first-line treatment of ED is oral phosphodiesterase-5 inhibitors. For those who do not respond to oral therapy, there is no defined 'step-ladder' escalation in alternative therapy. It is up to the physician to discuss the options with the patient or couple and reach a decision based on their preference.
\end{abstract}

Key words

Erectile dysfunction; phosphodiesterase 5 inhibitors; alprostadil

\section{Introduction}

Erectile dysfunction (ED) is a significant but neglected health problem in Bangladesh. Erectile dysfunction not only destroy the sexual life of an individual, but it is detrimental to a man's self-esteem, quality of life, and interpersonal relationships, and is increasingly considered an issue for the man and his female sexual partner [1].

1. Professor of Endocrinology Chittagong Medical College, Chittagong

2. Assistant Professor of Endocrinology Chittagong Medical College, Chittagong

Correspondence: Dr Abdus Saleque Mollah e-mail:mollahas@yahoo.com
ED is independently associated with cardiovascular (CV) events (angina, myocardial infarction, and stroke [2]. The economic burden of ED is not just limited to the cost of diagnosis and treatment. Other more subtle impacts on society that are difficult to quantify are lost time at work, decreased productivity and many more [3].

For more than last three decades effective oral drugs are available worldwide for treatment of ED, but unfortunately these drugs have been approved for use in Bangladesh very late. The aim of this review is to highlight the recent development in the management of ED.

\section{Definition}

According to the 1993 National Institute of Health Consensus Development panel on impotence in the United States of America, the term impotence was supplanted by erectile dysfunction (ED) [4]. The Second International Consultation on Sexual Dysfunction (ICSD2) defined ED as a 'consistent or recurrent inability of a man to attain and/or maintain penile erection sufficient for sexual activity' [5].

The condition must be present for a minimum of 3 months to establish the diagnosis. The exception to this is when ED is preceded by trauma or pelvic surgery. ED is part of a spectrum of male sexual dysfunction that encompasses sexual interest/desire dysfunction, early ejaculation, delayed ejaculation, anejaculation and orgasmic dysfunction.

\section{Classification}

Contemporary ED classification incorporates the aetiology into the classification system. An example of this was described by Lizza and Rosen (Table I) [6].

The initial hypothesis that ED had a purely psychogenic causality changed with our improved understanding of the physiology of penile erection. Views that organic disease accounted for most cases of ED (table II) became dominant in the 1980s. However, we currently recognise that the reality is probably somewhere in between, with both factors varying in importance in each individual patient. 
Table I : Classification of erectile dysfunction Organic

1. Vasculogenic

a) Arteriogenic

b) Cavernosal

c) Mixed

2. Endocrinological

3. Neurogenic

4. Anatomical

Psychogenic

1. Generalised type

a) Generalised unresponsiveness

i) Primary lack of sexual arousability

ii) Aging related decline in sexual arousability

b) Generalised inhibition

c) Chronic disorder of sexual intimacy

2. Situational type

a) Partner related

i) Lack of arousability in specific relationship

ii) Lack of arousability due to sexual object preference

iii) High central inhibition due partner conflict or treatment

b) Performance related

i) Associated with other sexual dysfunction/s

ii) Situation performance anxiety

c) Psychological distress or adjustment related

i) Associated with negative mood state or life stress

Table II : Diseases associated with erectile dysfunction

Cardiovascular disease

Atherosclerosis

Coronary artery disease

Hypertension

Neurological disease

Cerebrovascular disease

Epilepsy

Spinal injury

Dementias

Endocrine disease

Hyperprolactinaemia

Thyroid disease

Hypogonadism

Systemic disease

Diabetes mellitus

Chronic renal failure

Haemochromatosis

Liver cirrhosis

Arthritis

Malignancy

Other

Smoking

Alcohol

Surgery

Drugs

Depression

Penile abnormalities, eg. Peyronie's disease

\section{Epidemiology}

The worldwide prevalence of ED is very high and is expected to increase substantially in the aging populations of various regions over the next 25 years. In 1995, it was estimated that 152 million men worldwide had ED, and that by the year 2025, the number of men with ED would be about 322 million, an increase of nearly 170 million men. The greatest increases will be in the developing world, such as Africa, Asia and South America [7]. Establishing the prevalence of ED in these regions is important for understanding the need for services, which in turn depends on the functional expectations of men as they age.

The Massachusetts male ageing study was one of the first population-based studies of ED and demonstrated a $52 \%$ prevalence across all severities (1290 men aged 40-70 years) [8]. A more recent European study found a $30 \%$ prevalence of ED across eight European centres (3369 men aged 40-79 years) [9]. Studies on ED prevalence from countries across various regions of Asia, the Middle East and Africa where socio-cultural and religious characteristics are similar, have been documented [10-13]. For example, in three studies in Nigeria, prevalence rates of $57.4 \%, 50.7 \%$ and $46.9 \%$, respectively, have been reported [13-15]. Different definitions of ED, age distributions and risk factor profiles, as well as methodological differences, may explain much of the variance in reported prevalence rates [16]. Due to its sensitive nature ED may be under-reported. This is an absolute truth in Bangladesh where no data is available on the prevalence of ED.

\section{Risk factors}

Comorbidities such as heart disease, diabetes, dyslipidemia, hypertension, and depression have been described as primary risk factors for the development of ED [17-21]. Additionally, a number of modifiable lifestyle factors, including physical activity, smoking, alcohol consumption, diabetes control, and obesity, have been associated with ED [18-20, 22-27]. Certain medications may cause or contribute to erectile dysfunction in as many as $25 \%$ of men who present for evaluation table III [28]. 
Table III : Drugs associated with erectile dysfunction

\begin{tabular}{|c|c|}
\hline Drug class & Examples \\
\hline Diuretics & Thiazides, spironolactone \\
\hline Antihypertensive drugs & $\begin{array}{l}\text { Calcium-channel blockers, } \\
\text { beta-blockers, methyldopa, } \\
\text { clonidine, reserpine, guanethidine }\end{array}$ \\
\hline Cardiac or cholesterol drugs & Digoxin, gemfibrozil, clofibrate \\
\hline Antidepressants & $\begin{array}{l}\text { Selective serotonin-reuptake } \\
\text { inhibitors, tricyclic antidepressant } \\
\text { lithium, monoamine oxidase } \\
\text { inhibitors }\end{array}$ \\
\hline Tranquilizers & Butyrophenones, phenothiazines \\
\hline $\mathrm{H}_{2}$ antagonists & Ranitidine, cimetidine \\
\hline Hormones & $\begin{array}{l}\text { Progesterone, estrogens, } \\
\text { corticosteroids, luteinizing } \\
\text { hormone-releasing hormone } \\
\text { agonists, } 5 \alpha \text {-reductase inhibitors, } \\
\text { cyproterone acetate }\end{array}$ \\
\hline Cytotoxic agents & Methotrexate \\
\hline Immunomodulators & Interferon- $\alpha$ \\
\hline Anticholinergic agents & Disopyramide, anticonvulsants \\
\hline Recreational drugs & Alcohol, Cocaine \\
\hline
\end{tabular}

\section{Relevant anatomy and physiology penile erection}

\subsection{Corpora}

The penis contains three corpora the ventrally placed corpus spongiosum and two dorsal corpora cavernosa (CC) each surrounded by tunica albuginea. Collectively, the corpora are enclosed in Buck's fascia which contains the deep dorsal vein and a number of sensory nerves. Arterial inflow is provided by the internal pudendal arteries via the cavernosal arteries. The cavernosal arteries branch to form helicine arteries which open directly into the cavernosal spaces which contain a network of communicating venous sinuses. Blood drains from these cavernosal spaces into venules which coalesce to form larger veins which ultimately drain to the deep dorsal, cavernosal or crural veins [29].

\subsection{Neural pathways}

The neural pathways involved in penile erection are complex and effective co-ordination between them is necessary for adequate tumescence. The blood vessels and trabecular smooth muscle receive motor sympathetic and parasympathetic innervations via the thoracolumbar and lumbosacral regions of the peripheral nervous system, respectively [30].
The perineal striated muscles receive a somatic innervation via the lumbosacral somatics. The sympathetic supply reaches the penis via the cavernous nerves, having synapsed with preganglionic sympathetics from either the pelvic, cavernous, pudendal or hypogastric nerves. The parasympathetic supply arises predominately from the sacral spinal cord segments, emerging in the anterior roots as the nervi erigentes through which they reach the pelvic plexus. This plexus is vital in the regulation of penile erection. These complex neural pathways are mediated via a combination of adrenergic, cholinergic and non-adrenergic, noncholinergic nerves.

\subsection{Physiology of the penile erection}

Penile erection is determined by a delicate balance between contracting and relaxing factors at the level of the CC. In its flaccid state, the smooth muscle within both the penile arteries and the $\mathrm{CC}$ are contracted arterial inflow is limited and venous outflow is unobstructed. In response to the central processing of tactile, visual and olfactory stimuli, smooth muscle relaxation occurs resulting in a rapid arterial inflow to the lacunar spaces of the CC [31]. With progressive inflow, the trabecular walls and tunica albuginea expand and elongate, causing compression of the venules which pierce the tunica. This process of increasing inflow combined with a simultaneous venous outflow obstruction results in tumescence. Detumescence results from a reversal of this process with smooth muscle contraction in the $\mathrm{CC}$ resulting in a decrease in arterial inflow together with restoration of venous outflow.

Penile erection is under both central and local neuromediation [30]. A large number of substances have been demonstrated experimentally to act at the supraspinal level, these include dopamine, oxytocin, adrenocorticotropic hormone, nitric oxide, serotonin, gamma-aminobutyric acid and cannabinoids. Locally, a number of vasoactive mediators are released by the endothelial and smooth muscle cells of the CC. The final common pathway of these substances is to modulate intracellular calcium $(\mathrm{Ca} 2+)$ levels and/or alter the calcium sensitivity of proteins involved in smooth muscle contraction [30].

\section{Pathophysiology of erectile dysfunction}

Organic ED underlined by multifaceted, complex mechanisms, involving nerve, vascular, and hormonal signaling at its core [30]. Normal erectile function requires the coordination of psychological, hormonal, neurological, vascular, and cavernosal factors. Alteration in any one of these factors is sufficient to cause erectile dysfunction. Not uncommonly, a combination of factors is involved $[32,33]$. 
Molecular mechanism of penile smooth muscle relaxation [34]

Outflow from the parasympathetic nervous system leads to relaxation of the cavernous sinusoids in two ways, both of which increase the concentration of nitric oxide (NO) in smooth-muscle cells. First, nitric oxide is the neurotransmitter in nonadrenergic, noncholinergic (NANC) fibers, second, stimulation of endothelial nitric oxide synthase (eNOS) through cholinergic output causes increased production of nitric oxide. The nitric oxide produced in the endothelium then diffuses into the smooth-muscle cells. With the increase in nitric oxide content, the smooth-muscle cell decreases its intracellular calcium concentration through a pathway mediated by cyclic guanosine monophosphate (cGMP), which leads to relaxation. A separate mechanism that decreases the intracellular calcium level is mediated by cyclic adenosine monophosphate (cAMP). With increased cavernosal blood flow, as well as increased levels of vascular endothelial growth factor (VEGF), the endothelial release of nitric oxide is further sustained through the phosphatidylinositol 3 (PI3) kinase pathway. Active treatments include drugs that affect the cGMP pathway (phosphodiesterase [PDE] type 5 inhibitors and guanylyl cyclase agonists), the cAMP pathway (alprostadil), or both pathways (papaverine), along with neural-tone mediators (phentolamine and Rho kinase inhibitors). Parasympathetic outflow is impaired in patients with diabetes, depression, and central and peripheral neuropathic diseases that inhibit neural output; outflow is also impaired by destruction of the nonadrenergic, noncholinergic nerves themselves. Exposure to tobacco smoke and lower urinary tract symptoms of benign prostatic hyperplasia are associated with an increase in outflow from the sympathetic nervous system that inhibits relaxation forces. Lower urinary tract symptoms may also impair the nitric oxide content in the penis, prostate, and bladder and account for the association between such symptoms and erectile dysfunction. Diabetes, the metabolic syndrome, hyperlipidemias, atherosclerosis, and smoking also directly reduce the activity of nitric oxide synthase and induce apoptosis of endothelial and smoothmuscle cells.

\section{Evaluation}

A goal directed approach has been successfully used for the management of patients with erectile dysfunction [35]. The patient's medical and sexual history should be taken, and details of any concomitant medication, tobacco and alcohol consumption, and the presence of risk factors for erectile dysfunction (for example, vascular or surgical) should be noted. Preservation of nocturnal and early morning erections generally means that there is no organic basis for erectile dysfunction [36]. The differences between organic and psychogenic ED are shown in table IV [3].

The quality of erections during sleep can be assessed with portable home devices (such as Rigiscan) that measure changes in penile girth and rigidity, or in a sleep laboratory. Measurement of blood pressure, palpation of peripheral pulses, and a neurological examination should be undertaken, including the bulbocavernous reflex and anal sphincter tone. The secondary sexual characteristics should be examined for signs of hypogonadism and any local abnormality in the external genitalia should be noted. The penis should be palpated for Peyronie's plaques and the testes examined for size and consistency. Further investigations are likely to be guided by the clinical findings, but should include measurement of free testosterone, prolactin, TSH, LH and FSH concentrations. The basic work-up (minimal diagnostic evaluation) outlined in Fig: 1 must be performed in every patient with ED [37-38].

\section{Vascular evaluation of the penis}

$A$ complete diagnostic investigation, and therefore a full vascular assessment, may not be important for most patients, since only a few will be treated surgically [39]. The best minimally invasive method currently available for studying arterial blood supply to the penis is colour duplex Doppler ultrasound, which assesses the integrity of the arterial supply to the penis and provides some useful information on the veno-occlusive mechanism [40]. More precise assessment of this mechanism requires specialised invasive tests eg. cavernosometry and cavernosography which are performed if surgery is contemplated [39].

\section{Treatment}

Within the past the two decades, major advances have been made in the treatment of ED. Successful treatment naturally requires a patient who is willing to admit to himself and his partner that a problem exists. The patient also needs to be willing to be counseled, have the treatment options explained and then make an informed decision about therapy [37].

Treatment strategy can be categorized as

1. Changing habit and lifestyle

2. Psychosexual therapy

3. Pharmacological

4. Vacuam constriction device

5. Surgical treatment 


\subsection{Changing habit and lifestyle}

Encouraging regular exercise, healthy diet, cessation of smoking and moderating alcohol consumption can all be helpful. With regard to exercise, long distance cycling is a risk factor and an alternative form of exercise should be considered if vascular compromise is suspected, although changing the bicycle seat may also help [41].

\subsection{Psychosexual therapy}

Psychosexual therapy includes psychotherapy and sex therapy as described by Masters and Johnson [42]. However, modern sexologists argue that psychoanalytic therapy is rarely indicated and a symptom-orientated treatment is preferred by many psychologists. The main elements of symptom orientated treatment are explanation of the cause, reassurance, encouragement, and advice. Symptom orientated counseling has replaced the individual psychoanalytic therapy as the more effective treatment choice [43].

Table IV : Characteristics of organic and psychogenic erectile dysfunction

\begin{tabular}{lll|}
\hline Characteristic & Organic & Psychogenic \\
\hline $\begin{array}{l}\text { Age } \\
\text { Onset }\end{array}$ & $\begin{array}{l}\text { Older } \\
\text { Gradual (except in } \\
\text { trauma or surgery) }\end{array}$ & $\begin{array}{l}\text { Younger } \\
\text { Acute }\end{array}$ \\
$\begin{array}{l}\text { Circumstances } \\
\text { Symptom }\end{array}$ & $\begin{array}{l}\text { Consistent or } \\
\text { progressive }\end{array}$ & $\begin{array}{l}\text { Intermittent } \\
\text { Morning }\end{array}$ \\
erection & Poor & Rigid \\
Desire & Normal & Decreased \\
Organic risks & Present & Absent, variable \\
Partner problem & Secondary & At onset \\
Anxiety and fear & Secondary & Primary \\
\hline
\end{tabular}

\subsection{Pharmacological therapy}

\section{i) Phosphodiesterase 5 inhibitors (PDE5-Is)}

The PDE5-Is is currently used as a first line therapy for the treatment of ED. It is a selective inhibitor of PDE-5, which enhances the effect of nitric oxide to increase smooth muscle relaxation and inflow of blood to the corpus cavernosum. They are not initiators of erection and require sexual stimulation for an erection to occur. Efficacy is defined as rigidity sufficient for vaginal penetration.
Three potent selective PDE5-Is have been approved by the Federal Drug Administration (FDA) and European Medicines Agency (EMA) for the treatment of ED [43].

Sildenafil launched in 1998, was the first PDE5-I available. It is effective $30-60 \mathrm{~min}$ from administration. A heavy fatty meal may reduce or prolong absorption. It is administered in $25 \mathrm{mg}$, $50 \mathrm{mg}$ and $100 \mathrm{mg}$ doses. The recommended starting dose is $50 \mathrm{mg}$, which is adapted according to patient response and side-effects. Efficacy may last for up to 12 hours. In premarketing studies, after 24 wk of treatment in a dose-response study, improved erections were reported by $56 \%, 77 \%$, and $84 \%$ of men taking $25 \mathrm{mg}$, $50 \mathrm{mg}$ and $100 \mathrm{mg}$ of sildenafil, respectively, compared with $25 \%$ of men taking placebo. The efficacy of sildenafil in almost every subgroup of patients with ED has been well established in pre and postmarketing studies.

Tadalafil was licensed for ED in 2003. It is effective from $30 \mathrm{~min}$ after administration, but its peak efficacy occurs after about 2 hours. Efficacy is maintained for up to 36 hours. Its efficacy is not affected by food. It is administered in $10 \mathrm{mg}$ and $20 \mathrm{mg}$ doses. The recommended starting dose is $10 \mathrm{mg}$, which is adapted according to patient response and side effects. In premarketing dose response studies, improved erections were reported after $12 \mathrm{wk}$ of treatment by $67 \%$ and $81 \%$ of men taking $10 \mathrm{mg}$ and $20 \mathrm{mg}$ of tadalafil, respectively, compared with $35 \%$ of men taking placebo. The results were confirmed in postmarketing studies. Tadalafil also improved erections in difficult to treat subgroups.

Vardenafil was licensed for ED in 2003. It is effective $30 \mathrm{~min}$ from administration. A fatty meal ( $>57 \%$ in fat) reduces its effect. It is administered in $5 \mathrm{mg}, 10 \mathrm{mg}$ and $20 \mathrm{mg}$ doses. The recommended starting dose is $10 \mathrm{mg}$, which is adapted according to the response and side effects. In vitro, it is 10 fold more potent than sildenafil; however, this does not necessarily mean greater clinical efficacy. In premarketing dose response studies, improved erections after $12 \mathrm{wk}$ of treatment were reported by $66 \%, 76 \%$, and $80 \%$ of men taking $5 \mathrm{mg}, 10 \mathrm{mg}$ and $20 \mathrm{mg}$ of vardenafil, respectively, compared with $30 \%$ of men taking placebo. Efficacy was confirmed in postmarketing studies. Vardenafil also improved erections in difficult to treat subgroups. 


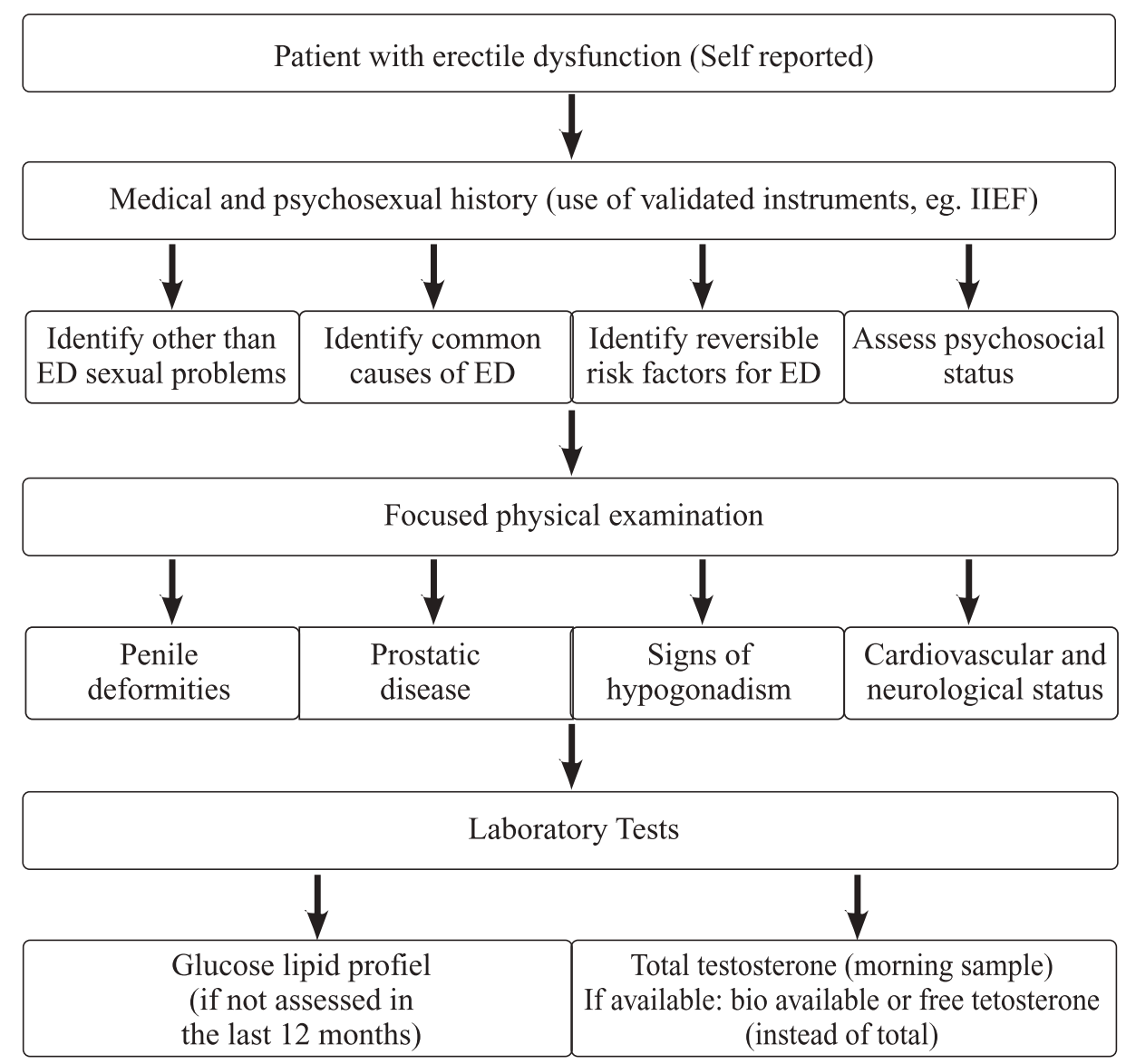

Fig 1: Basic diagnostic work-up in patients with erectile dysfunction $\mathrm{ED}=$ Erectile dysfunction; $\mathrm{IIEF}=$ International Index of Erectile Function

\section{Choice of or preference for different phosphodiesterase type 5 inhibitors}

The choice of a PDE5-I depends on the frequency of intercourse (occasional use or regular therapy, three to four times weekly) and the patient's personal experience with the agent. Consideration should be given to which drug better fits the patient's sexual habit with his partner to optimise response. Patients need to know whether a drug is short or long acting, its possible disadvantages, and how to use it. In a study on patients' PDE5 inhibitor preference by Eardley and colleagues' [44] it was reported that despite both sildenafil and tadalafil being effective more patients preferred tadalafil.

\section{On demand or chronic use of phosphodiesterase type 5 inhibitors}

Although PDE5-Is were initially introduced as on demand treatment, in 2008, tadalafil was also approved for continuous, everyday use in $2.5 \mathrm{mg}$ and $5 \mathrm{mg}$ doses. Two studies assessing daily use of $5 \mathrm{mg}$ and $10 \mathrm{mg}$ tadalafil for $12 \mathrm{wk}$ and daily use of $2.5 \mathrm{mg}$ and $5 \mathrm{mg}$ tadalafil for $24 \mathrm{wk}$ showed that daily dosing was well tolerated and significantly improved erectile function [45-46]. Similar results have been found in diabetic patients [47]. These studies, however, lacked an on demand treatment arm. Daily tadalafil provides an alternative to on demand dosing for couples who prefer spontaneous rather than scheduled sexual activity or who have frequent sexual activity. 
Daily dosing overcomes the requirement for dosing and sexual activity to be temporally linked. Other studies have shown that chronic but not on demand tadalafil treatment improved endothelial function, with sustained effects after its discontinuation. This finding was confirmed in another study of chronic sildenafil use in men with type 2 diabetes [48]. In contrast, a randomised clinical study found that once daily dosing of vardenafil at $10 \mathrm{mg} / \mathrm{d}$ did not offer any sustainable effect after cessation of treatment compared with on demand vardenafil in patients with mild to moderate ED [49].

\section{Adverse events}

Common adverse events include headache (10-16\%), flushing (5-12\%), dyspepsia (4-12\%), nasal congestion (1-10\%), and dizziness (2-3\%) [50]. Sildenafil and vardenafil have been associated with visual abnormalities in $<2 \%$ of patients, while tadalafil has been associated with back pain/myalgia in $6 \%$ of patients. Adverse events are generally mild in nature and selflimited by continuous use, and the dropout rate due to adverse events is similar to that seen with placebo.

\section{Cardiovascular safety}

Clinical trials and postmarketing data of all PDE5-Is have demonstrated no increase in myocardial infarction rates [48]. No PDE5-I has adversely affected total exercise time or time to ischemia during exercise testing in men with stable angina. In fact, they may improve exercise tests.

Nitrates are totally contraindicated with all PDE5-Is due to unpredictable hypotension. The duration of interaction between organic nitrates and PDE5-Is varies according to the PDE5-I and nitrate. If a patient develops angina while using a PDE5-I, other antiangina agents may be used instead of nitroglycerine or until the appropriate time has passed (24 hours for sildenafil or vardenafil and $48 \mathrm{~h}$ for tadalafil) [48]. Other contraindications are severe hepatic impairment, hypotension, recent history of stroke or MI, hereditary degenerative retinal disorders, hypersensitivity to the active substance or excipients, and other conditions where sexual activity is inadvisable [50]. Special precautions should be taken to use PDE5-Is in the following conditions: anatomical deformation of the penis (angulation, cavernosal fibrosis or Peyronie's disease) predisposition to priapism (sickle-cell anaemia, multiple myeloma, leukaemia) bleeding disorders or active peptic ulceration [50].

\section{Alpha blockers interactions}

The concomitant use of PDE5-Is with a-blockers may result in orthostatic hypotension under some conditions. The labelling for sildenafil currently includes a precaution advising that $50 \mathrm{mg}$ or $100 \mathrm{mg}$ (not $25 \mathrm{mg}$ ) of sildenafil should not be taken within 4 hours of taking an a blocker. The use of vardenafil with an a blocker is not recommended, however, coadministration of vardenafil with tamsulosin is not associated with clinically significant hypotension. Tadalafil is contraindicated in patients taking a blockers, except for tamsulosin [50]. Generally, the patient should be stable in his a blocker therapy before using a PDE5-I. The long-acting a blockers (doxazosin, terazosin) should be avoided in this concomitant use. Alfuzosin and tamsulosin are the preferred a blockers.

\section{Dosage adjustments}

Lower doses of PDE5-Is may be required in patients taking ketoconazole, itraconazole, erythromycin, clarithromycin, and HIV protease inhibitors (ritonavir, saquinavir) [43]. Higher doses of PDE5-Is may be necessary in patients taking rifampicin, phenobarbital, phenytoin, or carbamazepine. Kidney or hepatic dysfunction may require dose adjustments. In patients with hypogonadism, androgen supplementation improves erectile response.

\section{Management of nonresponders to phosphodiesterase type 5 inhibitors}

The two main reasons that patients fail to respond to a PDE5-I are either incorrect drug use or inefficacy of the drug [43]. Physicians should check that the patient is using a licensed medication and that the medication has been properly prescribed and correctly used (ie, that there is adequate sexual stimulation and dosage and enough time between taking the medication and an attempt at intercourse).

Provided that a patient is using a PDE5-I appropriately, efficacy can be improved in several ways, including modification of associated risk factors, treatment of associated hypogonadism, changing to another PDE5-I, or continuous use of a PDE5-I. Limited evidence supports using these interventions [51]. Additionally, an accumulating body of evidence supports the use of psychosexual educational counselling in combination with pharmaceutical treatments to further optimise response. 


\section{ii) Sublingual apomorphine}

Apomorphine is a dopamine D2-receptor agonist which acts in the CNS. The sublingual (SL) formulation is rapidly absorbed. Clinical trials have shown improvement in percentage of attempts resulting in successful sexual intercourse and an improvement [52]. A recent preference study suggests that patients prefer PDE5 inhibitors to apomorphine SL [53]. Therefore, its present use in the treatment of ED is diminishing and its future is uncertain

\section{iii) Intracavernosal injection therapy}

Alprostadil (prostaglandin E1) acts primarily on specific receptors found on cavernosal smooth cle cells [3]. It stimulates the activity of adenylate cyclase enzyme causing an elevation in the levels of intracellular cyclic adenosine monophosphate (cAMP). This leads to a fall in intracellular calcium and smooth muscle relaxation. It also reduces the release of noradrenaline (norepinephrine) from presynaptic noradrenergic nerve terminals with a resultant synergistic effect. Alprostadil can be combined for injection therapy with papaverine and phentolamine.

Papaverine was the first widely used drug as an intracavernosal agent. It inhibits breakdown of cGMP and cAMP by inhibiting PDE 2, 3 and 5. The resulting effect is a fall in intracellular calcium and cavernosal smooth muscle relaxation.

Phentolamine is a competitive inhibitor of 1 and 2 adrenoceptors. It also has an effect on serotonin receptors. When injected, phentolamine inhibits sympathetic neuronal activity. Its primary site of action is believed to be the arteriolar smooth muscle in the penis, leading to increased arteriolar blood flow. It can produce a useful synergistic effect when combined with alprostadil and papaverine.

\section{iv) Intraurethral and topical agents}

Intraurethral alprostadil is available through an applicator device in $125 \mu \mathrm{g}, 250 \mu \mathrm{g}, 500 \mu \mathrm{g}$ and 1000 $\mu \mathrm{g}$ doses [3]. It is applied after micturation directly into the urethra. The applicator releases a dissolvable pellet containing alprostadil. Patients are advised to massage their penis after instillation and avoid lying down for 10-15 minutes. Erection develops within 15 minutes of instillation and lasts 30-60 minutes. In some patients, a penile constriction ring may be applied to the base of the penis prior to instillation to enhance the erection. Common adverse effects are penile pain, urethral bleeding and pain in the upper thighs.
Single agent topical therapy such as nitroglycerin (glyceryl trinitrate) and alprostadil are available, but their efficacy has been low (approximately 40\%) in clinical trials [54]. Topical agents using a combination of agents such as aminophylline, dinitrate and co-dergocrine (ergoloid mesylates) have produced better efficacy in clinical trials (approximately 58\%) [55]. The role of intraurethral and topical agents in ED is diminishing, but they may be an alternative in patients who have not responded to PDE5 therapy but find injection therapy unacceptable.

\section{v) Androgen replacement therapy}

The routine use of androgen replacement therapy (ART) in the treatment of ED has been a controversial issue, because hypogonadism can be demonstrated in only a small proportion of men with 5.8 ED [56]. The efficacy of ART in enhancing erectile function is uncertain, although libido is improved [57]. ED patients with concurrent hypogonadism demonstrated by history, clinical examination and laboratory test may be commenced on ART after appropriate counselling. Potential detrimental effects on the cardiovascular system, prostate cancer and breast cancer risks must be disclosed to the patient.

ART can be administered through a variety of routes, including intramuscular injection, scrotal patches, transdermal patches and gel, as well as buccal and subcutaneous implants. Adverse effects of ART include peripheral oedema, raised haemat ocrit, gynaecomastia, headache, anxiety, acne, hirsutism, local reactions, cholestatic jaundice, hepatitis, hepatocellular carcinoma and peliosis hepatis.

ART is contraindicated in patients with suspected or confirmed prostate cancer, breast cancer and those who desire fertility [58]. The American Associanation of Clinical Endocrinologists (AACE) recommends 3-4 month follow ups in the first year and a 6-12 month follow up for the following 18 months [58]. At follow up, the assessments should include testosterone levels, digital rectal examination, an enquiry into lower urinary tract symptoms, PSA testing, breast examination, haematocrit testing and assessment of sleep apnoea.

\subsection{Vacuum constriction devices}

A vacuum constriction device (VCD) applies negative pressure to the penis to draw venous blood into the penis, which is then retained by application of a visible constricting band at the base of the penis. This method seems more acceptable to older patients [59]. 
Efficacy, defined by an erection satisfactory for intercourse, is as high as $90 \%$. Satisfaction rates range between 27 to 94 percent. After 2 years, only $50-64 \%$ of men continue to use VCDs. Most men who discontinue use of VCDs do so within $3 \mathrm{mo}$. The adverse effects associated with vacuum therapy are penile pain, numbness, and delayed ejaculation, these effects occur in $<30 \%$ of patients.

\subsection{Surgical therapy}

\section{i) Penile prostheses}

Surgical implantation of a penile prosthesis may be considered in patients who fail pharmacotherapy or who want a permanent solution. Prostheses are either malleable (semirigid) or inflatable (two or three piece). Most patients prefer the three piece inflatable devices because erections are more "natural," but these implants are much more expensive. Satisfaction rates of $70-87 \%$ are reported from patients after appropriate consultation [60]. The two main complications of penile prosthesis implantation are mechanical failure ( $<5 \%$ after 5 -yr followup with currently available three-piece prostheses) and infection [61].

\section{ii) Penile vascular surgery}

When arterial disease is the cause of ED, a bypass involving the inferior epigastric artery is the common technique utilised. Outcomes from surgical procedures have been difficult to compare in the literature because of the variation in diagnostic criteria, patient selection criteria, surgical technique, follow up duration and outcome assessments. Only a few studies used objective parameters, such as penile Doppler ultrasonography measurements before and after surgery and correlated these to clinical outcomes. The published results suggest that, although the initial patient satisfaction was high, the long term results have been rather disappointing [62]. Complications arising from this procedure include penile hyperaemia, altered sensation of the glans penis, infection and haematoma.
In veno occlusive disease, venous ligation and embolisation techniques have been utilised. Out comes are again difficult to compare for the same reasons as for bypass procedures. Venous embolisation both percutaneous and open - has also been attempted in veno-occlusive ED, with longterm success rates of 26-69 percent [63-64].

Techniques used in arterial disease have been shown to be effective only in men aged $<40$ years. This is regarded as a specialised surgery, which should be attempted only in large centres with specialist interest and experience.

Most men with ED will be treated with options that are not cause specific [65]. This approach requires a structured treatment strategy that depends on efficacy, safety, invasiveness, and cost as well as patient and partner satisfaction. The choice of treatment options must consider the effects on patient and partner satisfaction and other QoL factors as well as efficacy and safety. A treatment algorithm for ED is given in Fig : 2 .

\section{Conclusion and recommendation}

10.1 Diagnostic work up of erectile dysfunction (ED)

- Clinical history related to ED may help assess all sexual function domains and the effect of a specific treatment modality.

- Physical examination is needed in the initial assessment of ED to identify underlying medical conditions associated with ED.

- Routine laboratory tests, including glucose, lipid profile, testosterone, prolactin and TSH are required to identify and treat any reversible risk factors and modifiable lifestyle factors.

- $\quad$ Specific diagnostic tests are indicated by only a few conditions.

\subsection{Treatment of erectile dysfunction (ED)}

- Lifestyle changes and risk factor modification must precede or accompany ED treatment.

- If a curable cause of ED is found, treat the cause first.

- PDE5-Is are first line therapy. 


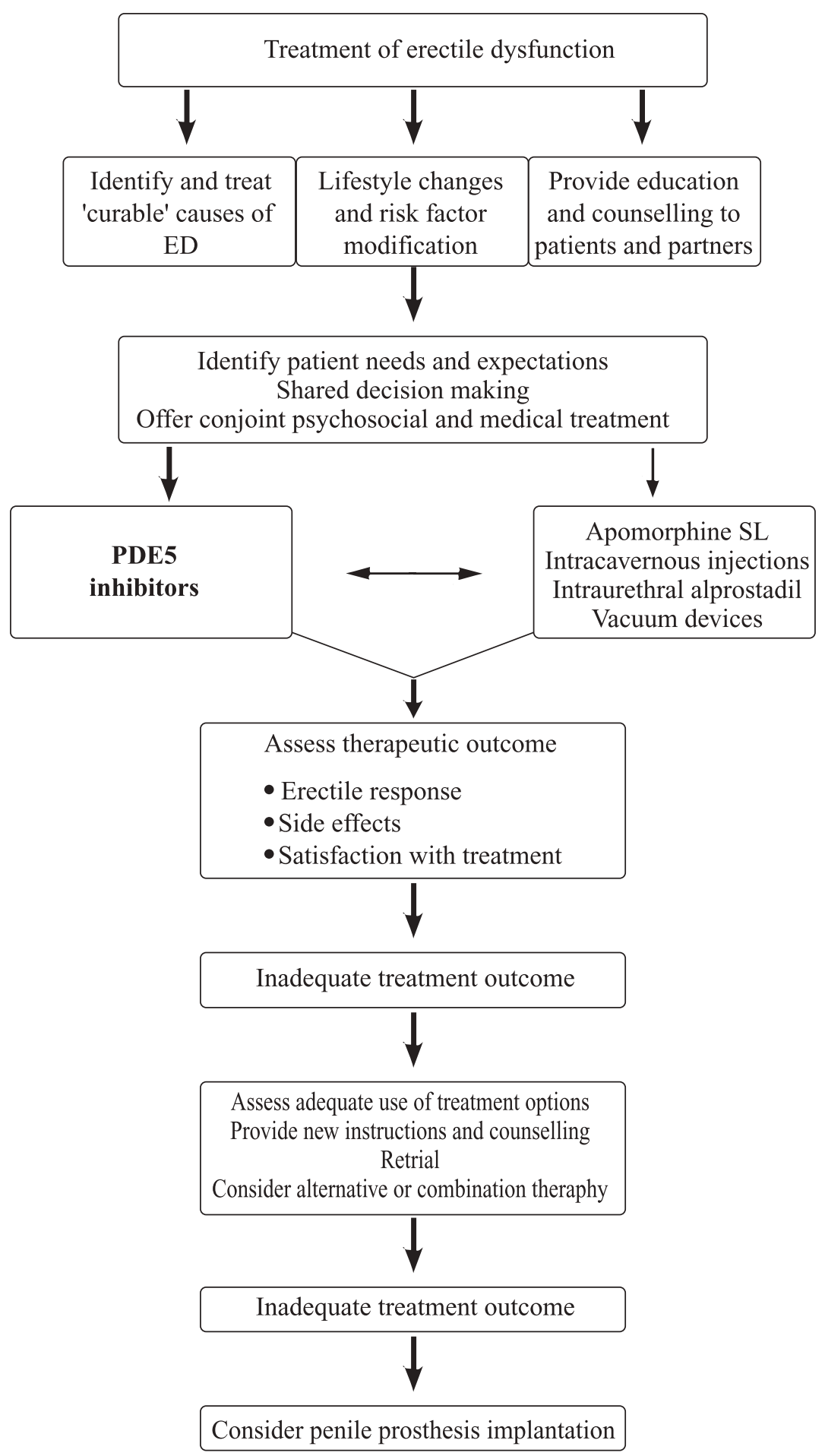

Fig 2 : Treatment algorithm for erectile dysfunction (ED) PDE5 $=$ Phosphodiesterase type 5 
- Daily administration of PDE5-Is may improve results and restore erectile function.

- Inadequate/incorrect prescription and poor patient education are the main causes of a lack of response to PDE5-Is.

- Testosterone replacement restores efficacy in hypogonadic nonresponders to PDE5-Is.

- Apomorphine can be used in mild to moderate $\mathrm{ED}$, psychogenic ED, or in patients with contraindications to PDE5-Is.

- A vacuum constriction device can be used in patients with stable relationship.

- Intracavernous injection is second line therapy.

- Penile implant is third line therapy.

- Surgery is rarely used except in specific indication.

\section{Disclosure}

The authors declared no competing interestes.

\section{References}

1. Wagner G, Fugl-Meyer KS, Fugl-Meyer AR. Impact of erectile dysfunction on quality of life: patient and partner perspective. Int J Impot Res 2000;12:S144-S146.

2. Hotaling JM, Walsh TJ, Macleod LC, Heckbert S, Pocobelli G, Wessells H, and White C. Erectile Dysfunction Is Not Independently Associated with Cardiovascular Death: Data from the Vitamins and Lifestyle (VITAL) Study. J Sex Med 2012;9:2104-2110

3. Sivalingam S, Hashim $\mathrm{H}$ and Schwaibold $\mathrm{H}$. An Overview of the Diagnosis and Treatment of Erectile Dysfunction. Drugs 2006; 66 (18): 2339-2355.

4. National Institute of Health Consensus Development Panel on Impotence. Proceedings of a Conference held December 7-9, 1992, Bethesda. Maryland JAMA 1993; 270: 83-90.

5. The Second International Consultation on Dysfunction. Sexual Medicine: Sexual Dysfunctions in Men and Women. 2004 Jun 28-Jul 1; Paris.

6. Lizza EF, Rosen RC. Definition and classification of erectile dysfunction: report of the Nomenclature Committee of the International Society of Impotence Research. Int J Imp Res 1999; 11: 141-144.

7. Ayta IA, McKinlay JB, Krane RJ. The likely worldwide increase in erectile dysfunction between 1995 and 2025 and some possible policy consequences. BJU Int 1999; 84: 50-56.
8. Feldman HA, Goldstein I, Hatzichristou DG, Krane RJ, McKinlay JB. Impotence and its medical and psychosocial correlates: results of the Massachusetts male aging study. J Urol 1994;151:54-61.

9. Corona G, Lee DM, Forti G, O'Connor DB, Maggi M, O’Neill TW, et al. Age-related changes in general and sexual health in middle-aged and older men: results from the European Male Ageing Study (EMAS). J Sex Med 2010;7:1362-1380.

10. Cheng JYW, Ng EML, Chen RYL, Ko JSN. Prevalence of erectile dysfunction in Asian populations: a meta-analysis. Int J Impot Res 2007; 19: 229-244.

11. Safarinejad MR. Prevalence and risk factors for erectile dysfunction in a population-based study in Iran. Int J Impot Res 2003; 15: 246-252.

12. Halayini IF, Al-Ghazo MA, Al-Azab R, BaniHani I, Matani YS, Barham AE et al. Erectile dysfunction in a Mediterranean country: results of an epidemiological survey of a representative sample of men. Int J Impot Res 2010; 22: 196-203.

13. Shaeer KZM, Osegbe DN, Siddiqui $\mathrm{SH}$, Razzaque A, Glasser DB, Jaguste V. Prevalence of erectile dysfunction and its correlates among men attending primary care clinics in three countries: Pakistan, Egypt, and Nigeria. Int J Impot Res 2003;15: S8-S14.

14. Dogunro S, Osegbe D, Jaguste VS. Epidemiology of erectile dysfunction (ED) and its correlates: a patient based study in Nigerian population. Int J Impot Res 2000;12: P47.

15. Oladiji F, Kayode OO and Parakoyi DB. Influence of socio-demographic characteristics on prevalence of erectile dysfunction in Nigeria. Int $\mathrm{J}$ Impot Res 2013;25:18-23.

16. Kubin $M$, Wagner $G$, Fugl-Meyer AR. Epidemiology of erectile dysfunction. Int $\mathrm{J}$ Impot Res 2003; 15: 63-71.

17. Seftel AD, Sun P, Swindle R. The prevalence of hypertension, hyperlipidemia, diabetes mellitus and depression in men with erectile dysfunction. J Urol 2004;171(6 Pt 1):2341-2345.

18. Lewis RW, Fugl-Meyer KS, Corona G, Hayes RD, Laumann EO, Moreira ED Jr, Rellini AH, Segraves T. Definitions/epidemiology/risk factors for sexual dysfunction. J Sex Med 2010;7(4 Pt 2):1598-1607.

19. Glina S, Sharlip ID, and Hellstrom WJG. Modifying Risk Factors to Prevent and Treat Erectile Dysfunctionjsm. J Sex Med 2013;10:115-119. 
20. Kupelian V, Shabsigh R, Araujo AB, O’Donnell AB, McKinlay JB. Erectile dysfunction as a predictor of the metabolic syndrome in aging men: results from the Massachusetts Male Aging Study. J Urol 2006;176:222-226.

21. Billups KL. Sexual dysfunction and cardiovascular disease: integrative concepts and strategies. Am J Cardiol 2005;96:Suppl 12B:57M$61 \mathrm{M}$.

22. McVary KT, Carrier S, Wessells H. Smoking and erectile dysfunction: evidence based analysis. J Urol 2001;166:1624-1632.

23. Kupelian V, Araujo AB, Chiu GR, Rosen RC, McKinlay JB. Relative contributions of modifiable risk factors to erectile dysfunction: Results from the Boston Area Community Health (BACH) Survey. Prev Med 2010;50:19-25.

24. Kalter-Leibovici O, Wainstein J, Ziv A, HarmanBohem I, Murad H, Raz I. Clinical, socioeconomic, and lifestyle parameters associated with erectile dysfunction among diabetic men. Diabetes Care 2005;28:1739-1744.

25. Gacci M, Eardley I, Giuliano F, Hatzichristou D, Kaplan SA, Maggi M, McVary KT, Mirone V, Porst H, Roehrborn CG. Critical analysis of the relationship between sexual dysfunctions and lower urinary tract symptoms due to benign prostatic hyperplasia. Eur Urol 2011;60:809-825.

26. Derby CA, Mohr BA, Goldstein I, Feldman HA, Johannes CB, McKinlay JB. Modifiable risk factors and erectile dysfunction: Can lifestyle changes modify risk? Urology 2000;1:302-306.

27. Cheng JY, Ng EM, Ko JS, Chen RY. Physical activity and erectile dysfunction: Meta-analysis of population-based studies. Int $\mathrm{J}$ Impot Res 2007;19:245-252.

28. Thomas A, Woodard C, Rovner ES, Wein AJ. Urologic complications of nonurologic medications. Urol Clin North Am 2003;30:123-131.

29. Ritchiea R, Sullivana M. Endothelins \& erectile dysfunction. Pharmacological Research 2011;63: 496-501.

30. Gratzke C, Angulo J, Chitaley K, Dai YT, Kim NN, Paick JS, et al. Anatomy, physiology, and pathophysiology of erectile dysfunction. J Sex Med 2010;7:445-475.

31. Andersson KE, Wagner G. Physiology of penile erection. Physiol Rev 1995;75:191-236.
32. Krane RJ, Goldstein I, Saenz de Tejada I. Impotence. N Engl J Med 1989;321:1648-1649.

33. Wagner G, de Tejada IS. Update on male erectile dysfunction (Clinical review). BMJ 1998;316:678-682.

34. McVary KT. Erectile Dysfunction. N Engl J Med 2007;357:2472-2481.

35. Lue TF. Impotence: a patient's goal-directed approach to treatment. World J Urol 1990;8:67-74.

36. Kirby RS, Impotence: diagnosis and management of male erectile dysfunction. BMJ 1994;308:957-961.

37. Hatzimouratidis K, Amar E, Eardley I, Giuliano F, Hatzichristou D, Montorsi F et al. Guidelines on Male Sexual Dysfunction: Erectile Dysfunction and Premature Ejaculation. EUROPEAN UROLOGY 2010;57:804-814.

38. Hatzichristou D, Hatzimouratidis K, Bekas M, Apostolidis A, Tzortzis V, Yannakoyorgos K. Diagnostic steps in the evaluation of patients with erectile dysfunction. J Urol 2002;168:615-620.

39. Li MK, Lau KO. Clinical evaluation of impotence. Ann Acad Med 1995;24:741-744.

40. Lewis RW, Mayda J II. Diagnosis and treatment of vasculogenic impotence. Acta Chir Hung 1994;34:231-241.

41. Sommer F, Konig D, Graft C, Schwarzer U, Bertram C, Klotz T, Engelmann U. Impotence and genital numbness in cyclists. Int $\mathrm{J}$ Sports Med 2001;22:410-413.

42. Masters WH, Johnson V. Human sexual inadequacy. Boston, Little, Brown \& Co., 1970.

43. Hatzimouratidis $\mathrm{K}$, Hatzichristou DG. A comparative review of the options for treatment of erectile dysfunction: which treatment for which patient? Drugs 2005;65:1621-1650.

44. Eardley I, Mirone V, Montorsi F, et al. An open label, multicentre, randomised, crossover study comparing sildenafil citrate and tadalafil for treating erectile dysfunction in men naive to phosphodiesterase 5 inhibitor therapy. BJU Int 2005; 96:1323-1332.

45. Porst H, Giuliano F, Glina S, et al. Evaluation of the efficacy and safety of once-a-day dosing of tadalafil $5 \mathrm{mg}$ and $10 \mathrm{mg}$ in the treatment of erectile dysfunction: results of a multicenter, randomized, doubleblind, placebocontrolled trial. Eur Urol 2006;50:351-359. 
46. Rajfer J, Aliotta PJ, Steidle CP, Fitch III WP, Zhao Y, Yu A. Tadalafil dosed once a day in men with erectile dysfunction: a randomized, doubleblind, placebo-controlled study in the US. Int J Impot Res 2007;19:95-103.

47. Hatzichristou D, Gambla M, Rubio-Aurioles E, et al. Efficacy of tadalafil once daily in men with diabetes mellitus and erectile dysfunction. Diabet Med 2008;25:138-146.

48. Vlachopoulos C, Ioakeimidis N, Rokkas K, Stefanadis C. Cardiovascular effects of phosphodiesterase type 5 inhibitors. J Sex Med 2009;6: 658-674.

49. Zumbe' J, Porst H, Sommer F, Grohmann W, Beneke M, Ulbrich E. Comparable efficacy of oncedaily versus on-demand vardenafil in men with mild-to-moderate erectile dysfunction: findings of the RESTORE study. Eur Urol 2008;54:204-212.

50. Wespes E, Amar E, Hatzichristou D, et al. Guidelines of erectile dysfunction: European Association of Urology 2006 [online]. patient must be focused beyond just the restoration Available from URL: http://www.uroweb.org/index.php?.stof penile erections. The state of mental health of the ructure id = 140 [Accessed 2013 Mar 11].

51. Shabsigh R, Kaufman JM, Steidle C, PadmaNathan H. Randomized study of testosterone gel as adjunctive therapy to sildenafil in hypogonadal men with erectile dysfunction who do not respond to sildenafil alone. J Urol 2004;172:658-663.

52. Dula E, Bukofzer S, Perdol R. Double blind, crossover comparison of $3 \mathrm{mg}$ apomorphine SL with placebo and with $4 \mathrm{mg}$ apomorphine SL in male erectile dysfunction. Eur Urol 2001; 39: 558-564

53. Eardley I, Wright $P$, Macdonagh R. An open label, randomised, flexible dose, crossover study to assess the comparative efficacy and safety of sildenafil citrate and apomorphine hydrochloride in men with erectile dysfunction. BJU Int 2004; 93: 1271-1275.

54. Goldstein I, Payton TR, Schecter PJ. A double blind, placebo controlled, efficacy and safety study of topical gel formulation of $1 \%$ alprostadil (TopiglanU) for in-office treatment of erec- tile dysfunction. Urology 2001; 57: 301-304.
55. Gomaa A, Shalaby M, Osman M, et al. Topical treatment of erectile dysfunction: randomised double blind placebo controlled trial of cream containing aminophylline, isosorbide dinitrate and codergocrine mesylate. BMJ 1996; 312: 1512-1515.

56. Buvat J, Lemaire A. Endocrine screening in 1022 men with erectile dysfunction: clinical significance and cost-effective strategy. J Urol 1997; 158: $1764-1767$.

57. Tenover JL. Testosterone replacement therapy in older men. Int J Androl 1999; 22: 300-306.

58. American Association of Clinical Endocrinologists Medical Guidelines for Clinical Practice for the Evaluation and Treatment of Hypogonadism in Adult Male Patients. Endocr Pract 2002; 8: 439-456.

59. Levine LA, Dimitriou RJ. Vacuum constriction and external erection devices in erectile dysfunction. Urol Clin North Am2001;28:335-341.

60. Montague DK, Angermeier KW. Penile prosthesis implantation. Urol Clin North Am 2001;28:355-361.

61. Montorsi F, Rigatti P, Carmignani G, et al. AMS three-piece inflatable implants for erectile dysfunction: a long-term multi-institutional study in 200 consecutive patients. Eur Urol 2000;37:50-55.

62. Konnak JW, Ohl DA. Microsurgical penile revascularization using central corporeal penile artery. J Urol 1989; 142: 305-308.

63. Arjona M, Osteros R, Zarca M. Percutaneous embolisation for erectile dysfunction due to venous leakage: prognostic factors for good therapeutic results. Eur Urol 2001; 39: 15-19.

64. Miwa Y, Shioyama R, Itou Y. Pelvic venoablation with ethanol for the treatment of erectile dysfunction due to venoocclusive dysfunction. Urology 2001; 58: 76-79.

65. Lue TF, Giuliano F, Montorsi F, et al. Summary of the recommendations on sexual dysfunctions in men. J Sex Med 2004;1:6-23. 